
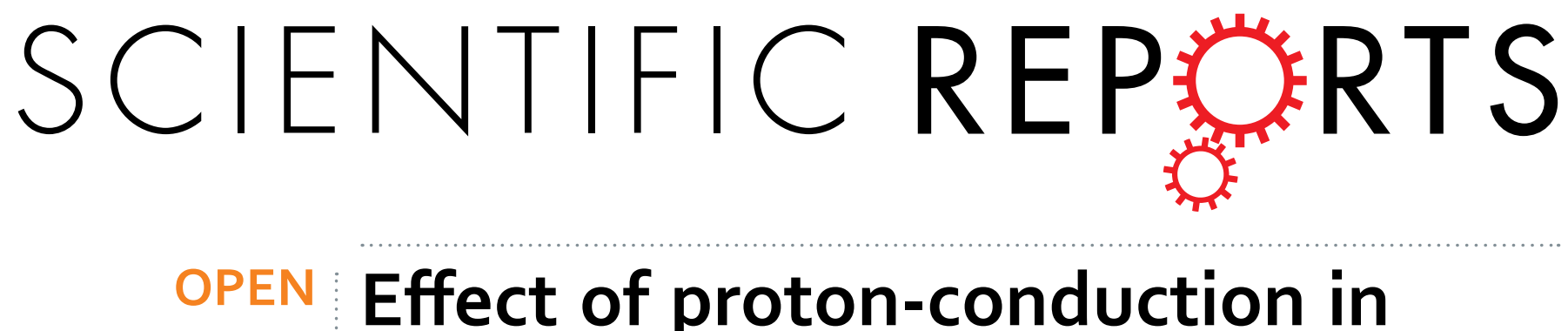

\title{
Effect of proton-conduction in electrolyte on electric efficiency of multi-stage solid oxide fuel cells
}

Received: 31 March 2015

Accepted: 06 July 2015

Published: 28 July 2015

\author{
Yoshio Matsuzaki ${ }^{1,2}$, Yuya Tachikawa ${ }^{3}$, Takaaki Somekawa ${ }^{1,4}$, Toru Hatae ${ }^{1}$, \\ Hiroshige Matsumoto ${ }^{3}$, Shunsuke Taniguchi ${ }^{5}$ \& Kazunari Sasaki ${ }^{2,3,4,5}$
}

Solid oxide fuel cells (SOFCs) are promising electrochemical devices that enable the highest fuelto-electricity conversion efficiencies under high operating temperatures. The concept of multi-stage electrochemical oxidation using SOFCs has been proposed and studied over the past several decades for further improving the electrical efficiency. However, the improvement is limited by fuel dilution downstream of the fuel flow. Therefore, evolved technologies are required to achieve considerably higher electrical efficiencies. Here we present an innovative concept for a critically-high fuel-toelectricity conversion efficiency of up to $85 \%$ based on the lower heating value (LHV), in which a high-temperature multi-stage electrochemical oxidation is combined with a proton-conducting solid electrolyte. Switching a solid electrolyte material from a conventional oxide-ion conducting material to a proton-conducting material under the high-temperature multi-stage electrochemical oxidation mechanism has proven to be highly advantageous for the electrical efficiency. The DC efficiency of $85 \%$ (LHV) corresponds to a net AC efficiency of approximately $76 \%$ (LHV), where the net AC efficiency refers to the transmission-end AC efficiency. This evolved concept will yield a considerably higher efficiency with a much smaller generation capacity than the state-of-the-art several tens-ofMW-class most advanced combined cycle (MACC).

To further enhance the electrical efficiency of solid oxide fuel cells (SOFCs), which enable the highest fuel-to-electricity conversion efficiencies under high operating temperatures ${ }^{1-5}$, it is necessary to increase the fuel utilization ratio $(U f)$ which refers to the quantity ratio of consumed fuel to supplied fuel. However, a high $U f$ (for example $90 \%$ or more) involves a considerable risk of running out of fuel at some cells in a stack and causing the oxidation of $\mathrm{Ni}$ in the Ni-YSZ (Yttria-Stabilized Zirconia) cermet typically used as the anode material, resulting in irreversible degradation. The primary reason for running out of fuel at some cells under a high $U f$ is the non-uniformity of the fuel distribution in the fuel cell stack. The risk is sufficiently low when the $U f$ in a stack is controlled to be approximately $75 \%$ or less.

Solid oxide fuel cells with a multi-stage electrochemical oxidation mechanism have been studied and developed over the past couple of decades to increase electrical efficiencies ${ }^{6-9}$. In the case of multi-stage electrochemical oxidation, the fuel supplied to an earlier stack placed upstream of the fuel flow is partially consumed through electrochemical oxidation in the stack and successively supplied to a latter stack placed downstream (Fig. 1). Then, the unutilized fuel from the earlier stack is delivered to the subsequent

${ }^{1}$ Fundamental Technology Department, Tokyo Gas Co., Ltd., 1-7-7 Suehiro-cho, Tsurumi-ku, Yokohama City, Kanagawa 230-0045, Japan. ${ }^{2}$ Next-generation Fuel Cell Research Center, Kyushu University, 744 Motooka, Nishi-ku, Fukuoka City, Fukuoka 819-0395, Japan. 3International Institute for Carbon-Neutral Energy Research (WPI-I²CNER), Kyushu University, 744 Motooka, Nishi-ku, Fukuoka City, Fukuoka 819-0395, Japan. 4Faculty of Engineering, Kyushu University, 744 Motooka, Nishi-ku, Fukuoka City, Fukuoka 819-0395, Japan. 5International Research Center for Hydrogen Energy, Kyushu University, 744 Motooka, Nishi-ku, Fukuoka City, Fukuoka 8190395, Japan. Correspondence and requests for materials should be addressed to Y.M. (email: matuzaki@tokyogas.co.jp). 


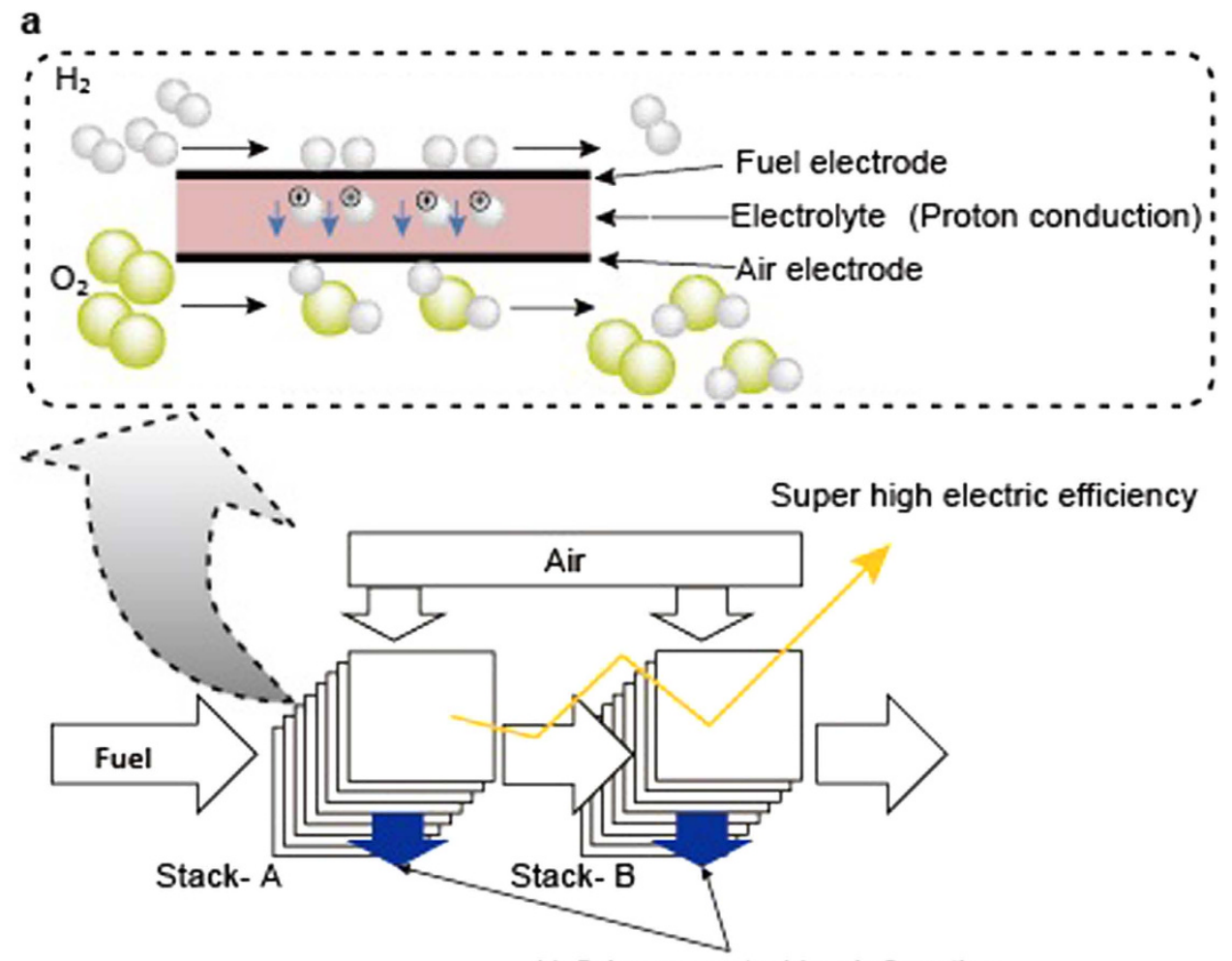

$\mathrm{H}_{2} \mathrm{O}$ is generated in air flow line.
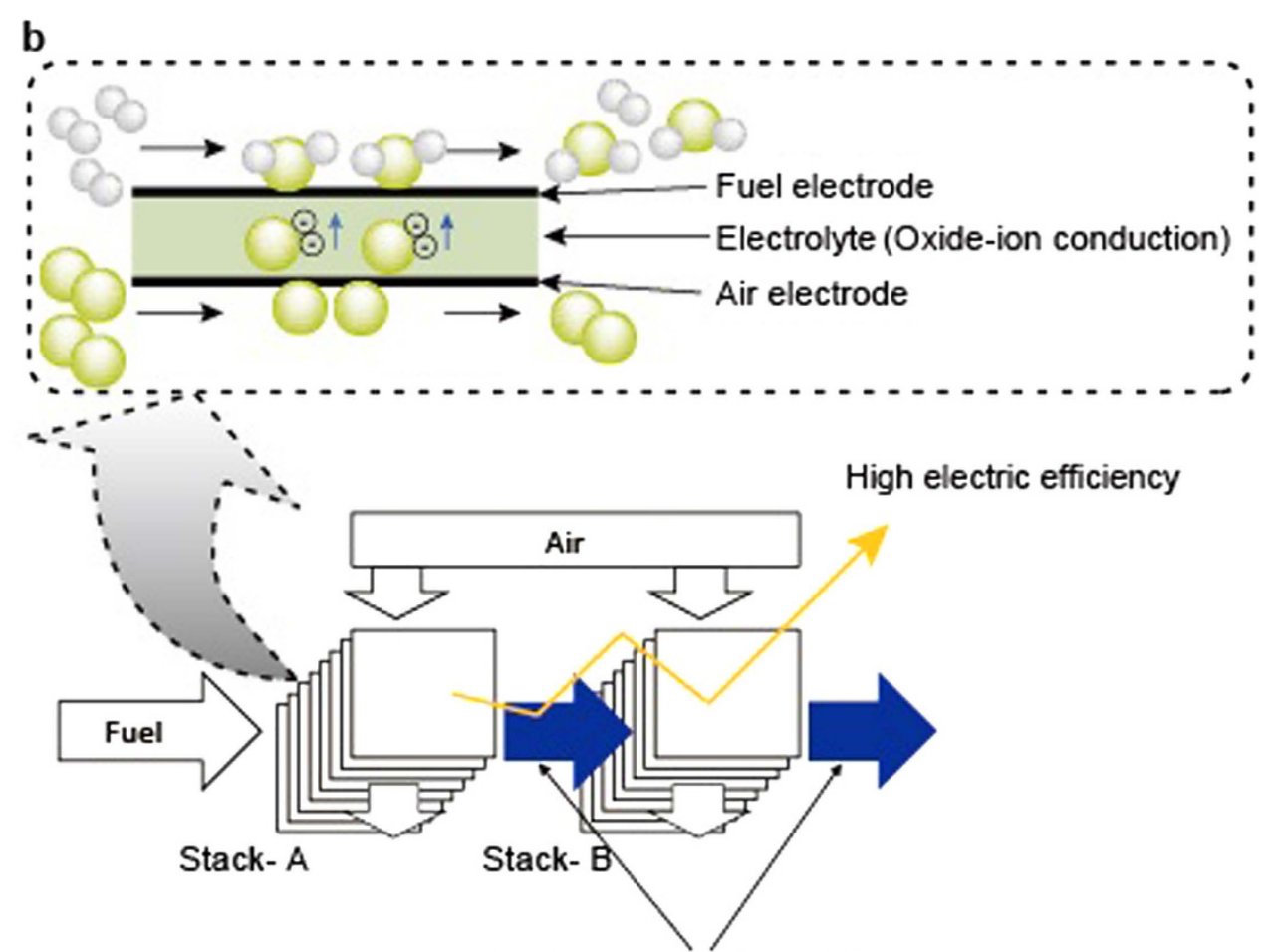

\section{$\mathrm{H}_{2} \mathrm{O}$ is generated in fuel flow line.}

Figure 1. Schematic of the evolved concept presented in this work compared with the conventional two-stage electrochemical oxidation. (a) Evolved concept: high-temperature multi-stage electrochemical oxidation with proton-conducting oxide as an electrolyte (given as a two-stage example). The inserted magnification shows the mechanism of $\mathrm{H}_{2} \mathrm{O}$ production at the air electrode side. (b) Conventional multistage method with an oxide-ion conducting oxide as an electrolyte (given as a two-stage example). The inserted magnification shows the mechanism of $\mathrm{H}_{2} \mathrm{O}$ production at the fuel electrode side. 
stack with zero waste, which results in increasing the $U f$ in the system while maintaining suppressed $U f$ in the respective stacks. Thus even with a $U f$ of the respective stacks of $75 \%$ or less, the multi-stage electrochemical oxidation technique enables entire system to operate at a $U f$ of $90 \%$ or more ${ }^{8}$. SOFCs with high electrical efficiencies of $68 \%$ (LHV, gross DC of the stack) and 60\% (LHV, net AC of the system) have been reported ${ }^{10,11}$. The stack is known to have a two-stage electrochemical oxidation mechanism. Although this mechanism is effective, it has significant limitations due to the large dilution of the fuel. For further improvement in efficiencies with the multi-stage mechanism, "UltraFuelCell" has been proposed by U.S. Department of Energy (DOE), which combines the multi-stage SOFC with a gas turbine, and has a power generation capacity of $4 \mathrm{MW}^{8}$.

SOFCs have oxide-ion conducting metal-oxide such as stabilized zirconia as electrolyte materials ${ }^{2}$, and they typically operate at temperatures higher than around $973.15 \mathrm{~K}$. To reduce the operating temperature for improving the long-term stability, it is necessary to reduce the thickness of the electrolyte or to develop new electrolyte materials that have sufficiently high ionic conductivities even at the reduced temperatures ${ }^{12-15}$. As a kind of candidate materials for the new electrolyte, proton-conducting solid electrolytes have been studied ${ }^{16-20}$. Recently several studies have reported promising SOFC performances with proton-conducting electrolytes ${ }^{21,22}$.

In this work, we investigate an evolved concept for a critically-high fuel-to-electricity conversion efficiency, in which a high-temperature multi-stage electrochemical oxidation is combined with a proton-conducting solid electrolyte. Based on the most basic design of the multistage configuration, i.e., two-stage configuration, we have successfully shown the important findings and promising results on the electrical efficiency; we have demonstrated that simply switching a solid electrolyte material from a conventional oxide-ion conducting material to a proton-conducting material under the high-temperature multi-stage electrochemical oxidation mechanism results in highly advantageous for the electrical efficiency.

\section{Results}

A parametric study based on a symbolic analysis for the evolved concept. A schematic illustration of the evolved concept that we propose in this work, including the combination of high-temperature multi-stage electrochemical oxidation and a proton-conducting solid electrolyte, is shown in Fig. 1a, and it is compared with a conventional oxide-ion conducting electrolyte as shown in Fig. 1b. The inserted magnifications in Fig. 1a,b show the mechanism of steam generation at the air and fuel electrode sides, respectively. Because there is no steam generation in principle at the fuel electrode and no dilution of fuel by the generated steam, especially downstream, the combination of the high-temperature multi-stage electrochemical oxidation and the proton-conducting solid electrolyte is expected to enable outstandingly high electric efficiencies (Fig. 1a).

Therefore, we have investigated the capability of the combination for critically-high electric efficiencies by a parametric study based on a symbolic analysis, the method of which is described in the section of "Methods". The most promising results obtained through the symbolic analysis were further evaluated by a chemical process simulator, Aspen Plus, based on a numerical analysis, the method of which is also described in the section of "Methods", to test the feasibility of the critically high-efficient power generation. The area specific resistance $(A S R)$ of the respective stacks is assumed to be $0.383 \mathrm{ohm} \mathrm{cm}^{2}$ at a sufficiently low $U f$ and at a temperature of $1,000 \mathrm{~K}$. As described in the section of "Methods", we defined the $A S R$ of a single stack in individual use at a sufficiently low $U f$ as $A S R_{\mathrm{O}}$. The $A S R_{\mathrm{O}}$ value of $0.383 \mathrm{ohm}$ $\mathrm{cm}^{2}$ is considered to be feasible for SOFC stacks ${ }^{2,23}$. Through the symbolic analysis, the electrical efficiency of a single stack in individual use with the $A S R_{\mathrm{O}}$ value is estimated to be $61 \%$ (LHV, gross DC) at a $U f$ of $75 \%$, which corresponds to a net AC efficiency of $55 \%$ (LHV).

In the case of two-stage electrochemical oxidation, the $U f$ in stack- A placed upstream of the fuel, $U f_{\mathrm{A}}$, and the $U f$ in stack- B placed downstream, $U f_{\mathrm{B}}$, are expressed as functions of $U f_{\mathrm{T}}$ and $r$, where $U f_{\mathrm{T}}$ is the $U f$ in the entire system and $r$ is the ratio of the fuel consumption in stack- B to stack- A. If the current density is equal in both stacks, the $r$ value equals to the ratio of the active electrode area in stack- B to stack- A. In order to simplify the discussion, a fuel is assumed to be hydrogen temporarily. When the fuel is supplied to the inlet of stack- $A$ at a rate of $Q\left[\mathrm{~mol} \mathrm{sec}^{-1}\right]$, unutilized fuel will be supplied to the inlet of stack- $\mathrm{B}$ at a rate of $\mathrm{Q} \cdot\left(1-U f_{\mathrm{A}}\right)$, and then will be used in stack- $\mathrm{B}$ at a rate of $Q \cdot\left(1-U f_{\mathrm{A}}\right) \cdot U f_{\mathrm{B}}$. A total consumption rate of the fuel is the sum of the consumption rates in stacks- A and $-\mathrm{B}, \mathrm{Q} \cdot\left(1-U f_{\mathrm{A}}\right) \cdot U f_{\mathrm{B}}+Q \cdot U f_{\mathrm{A}}$, which should be divided by $Q$ to give $U f_{\mathrm{T}}$.

$$
U f_{\mathrm{T}}=U f_{\mathrm{A}}+U f_{\mathrm{B}}-U f_{\mathrm{A}} \cdot U f_{\mathrm{B}}
$$

In addition, $r$ is defined as consumption ratio of fuel in stack- B to that in stack- $\mathrm{A}$, so that the following equation is derived.

$$
r=\frac{\left(1-U f_{\mathrm{A}}\right) \cdot U f_{\mathrm{B}}}{U f_{\mathrm{A}}}
$$




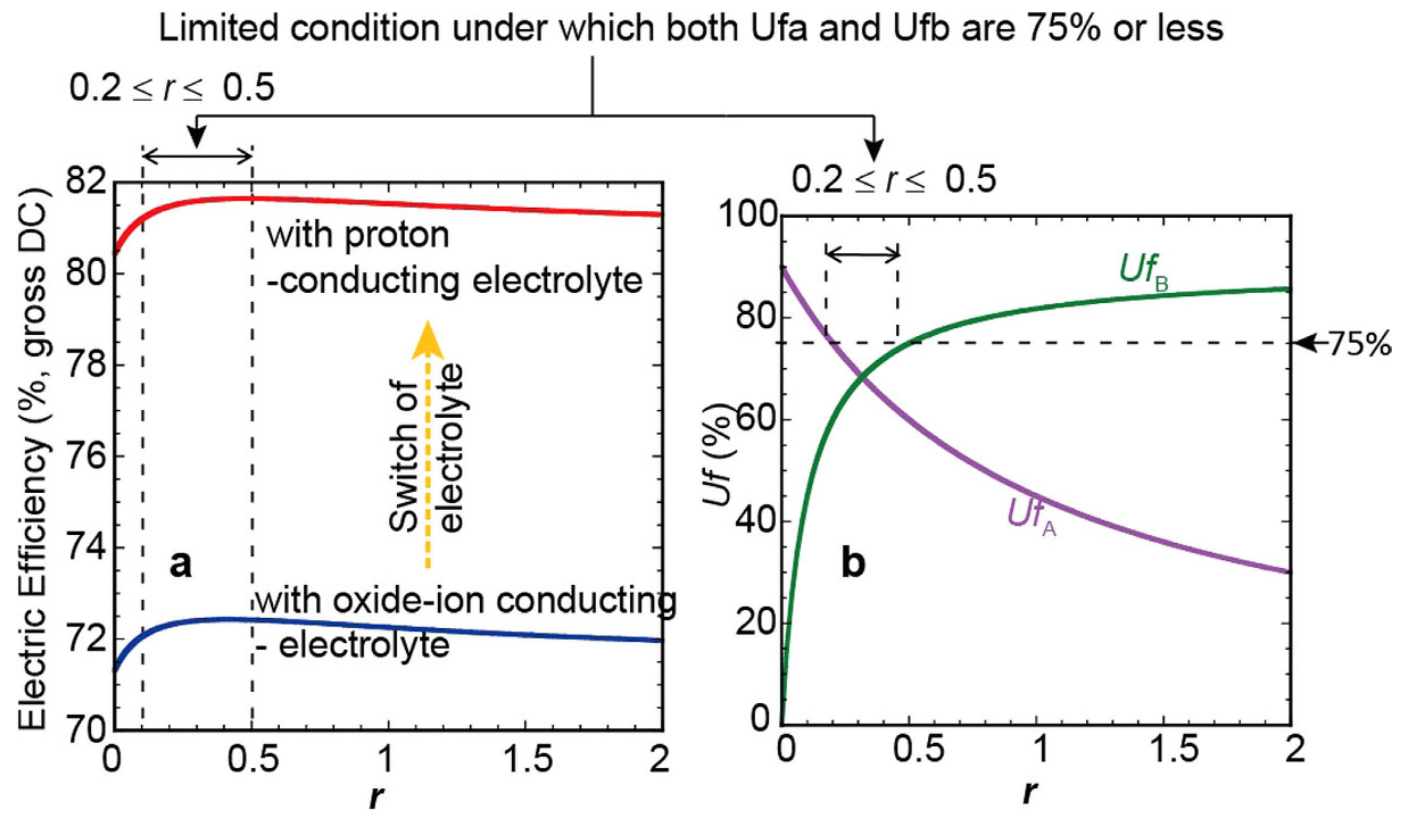

Figure 2. Electrical efficiencies with different types of charge-carrier (ion) in electrolytes in the case of the two-stage electrochemical oxidation, and the $\boldsymbol{U} \boldsymbol{f}$ of each stack. (a) The electrical efficiencies with a proton-conducting electrolyte and with an oxide-ion conducting electrolyte. (b) $U f_{\mathrm{A}}$ and $U f_{\mathrm{B}}$ as functions of $r$. Within the limited range of $0.2 \leq r \leq 0.5$, both $U f_{\mathrm{A}}$ and $U f_{\mathrm{B}}$ have values of less than or equal to $75 \%$ simultaneously with a $U f_{\mathrm{T}}$ of $90 \%$.

By solving the simultaneous equations (1) and (2), $U f_{\mathrm{A}}$ and $U f_{\mathrm{B}}$ can be obtained as functions of $r$ and $U f_{\mathrm{T}}$, which are expressed as equations (3) and (4), respectively. Equations (3) and (4) hold validity also for the case of the other fuels on the basis of Faraday's law.

$$
\begin{gathered}
U f_{\mathrm{A}}=\frac{U f_{\mathrm{T}}}{1+r} \\
U f_{\mathrm{B}}=\frac{r \cdot U f_{\mathrm{T}}}{1+r-U f_{\mathrm{T}}}
\end{gathered}
$$

As described in the section of "Methods", the electrical efficiency also can be expressed as a function of $r$ and $U f_{\text {T. }}$ At a $U f_{\mathrm{T}}$ of $90 \%$, the electrical efficiency with methane as a fuel and the $U f$ in each stack were obtained as functions of $r$ for the case of two-stage electrochemical oxidation through symbolic analysis (Fig. 2), where the partial pressure of $\mathrm{H}_{2} \mathrm{O}$ in air was assumed to be $2 \%$. A remarkable increase in the electrical efficiency was observed simply by switching the type of charge-carrier (ion) in the electrolyte (Fig. 2a). This result indicates that the development of proton-conducting solid electrolyte with a high protonic transport number is important for realizing a critically-high efficiency.

The maximum electrical efficiency in the case of a proton-conducting electrolyte was found to be as high as $81.6 \%$ (LHV, gross DC) at an $r$ of 0.5 . It has become clear that there is a specific range of $r$, $0.2 \leq r \leq 0.5$, in which it is possible to control $U f_{\mathrm{A}}$ and $U f_{\mathrm{B}}$ simultaneously to $75 \%$ or less even with a $U f_{\mathrm{T}}$ of $90 \%$ (Fig. 2b). Thus, the electric efficiency is found to have outstandingly high values in the case of a proton-conducting electrolyte without a $U f$ of higher than $75 \%$ for each stack if the $r$ value is adequately selected.

The efficiency and $U f$ at $r=0.5$ are compared with the efficiency and $U f$ of single- and two-stage electrochemical oxidations with an oxide-ion conducting electrolyte (Fig. 3). $U f_{\mathrm{A}}$ and $U f_{\mathrm{B}}$ are calculated to be $60 \%$ and $75 \%$, respectively, at a $U f_{\mathrm{T}}$ of $90 \%$. There are two types of mechanisms for reaching a critically-high efficiency; one is by the two-stage configuration, and the other is by the application of a proton-conducting electrolyte to the two-stage configuration (Fig. 3). Therefore, the symbolic analysis suggested that the evolved concept causes conventional SOFC stacks with electrical efficiencies of $61.1 \%$ (LHV, gross DC) in individual use to have significantly higher electrical efficiency of $81.6 \%$ (LHV, gross DC), even within a Uf range of $75 \%$ or less in each respective stack.

Feasibility of the super-efficient power generation. To study the feasibility of the critically-high efficiency predicted by the symbolic analysis, we have conducted a numerical experiment (chemical 


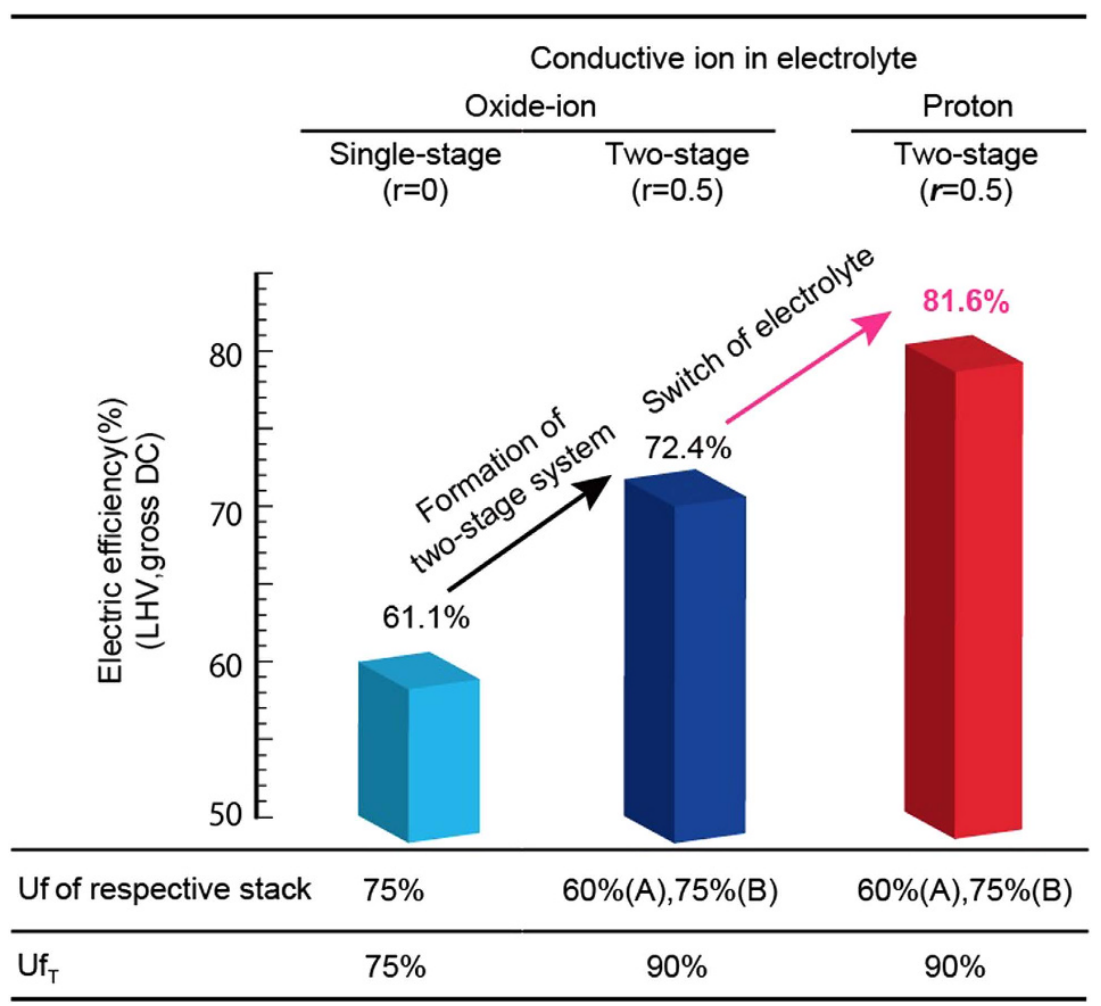

Figure 3. Main results from the symbolic analysis. The electrical efficiencies, the $U f$ of each stack, and $U f_{\mathrm{T}}$ are listed for comparisons between the single- and two-stage electrochemical oxidation and between the oxide-ion conducting electrolyte and proton-conducting electrolyte. Configuration of the two-stage system and applying the proton-conducting electrolyte to the configuration enhanced the electrical efficiency from $61.1 \%$ to $81.6 \%$ (LHV, gross DC).

process simulation) which simulates supplying methane as a fuel to stack- A at the rate of $0.01 \mathrm{~mol}$ $\mathrm{sec}^{-1}$ mixed with $\mathrm{H}_{2} \mathrm{O}$ under the condition of $r=0.5$ and $U f_{\mathrm{T}}=90 \%$ (Fig. $4 \mathrm{~b}$ ). The $r$ value of 0.5 gave the maximum electrical efficiency in Fig. 2a. This condition corresponds to the $U f_{\mathrm{A}}$ and $U f_{\mathrm{B}}$ of $60 \%$ and $75 \%$, respectively. The numerical experiment was conducted in AspenPlus Ver. 7.3. The molar flow rate of methane corresponds to $7.99 \mathrm{~kW}$ (LHV) of calorific value, and the faradaic current and cell voltage dictate the electrical output power of each stack. The electrical output powers of stacks- A and -B were calculated to be 4.4 and $2.1 \mathrm{~kW}$, respectively at a current density of $0.25 \mathrm{~A} \mathrm{~cm}^{-2}$ (Fig. $4 \mathrm{c}$ ). The electrical efficiency is given as a function of these output powers and the calorific value. The electrical efficiency thus calculated through the numerical simulation was $81.6 \%$ (LHV, gross DC) which corresponds well with the value predicted by the symbolic analysis. In this manner the critically-high efficiency has been reproduced by the numerical simulation.

Fuel cells with proton-conducting electrolytes cannot use $\mathrm{CO}$ as a fuel directly ${ }^{2}$. Therefore, the equilibrium composition of the fuel especially at the downstream stack (stack- B) has a significant impact on the feasibility of a critically-high efficiency. $\mathrm{CH}_{4}$ reacts with $\mathrm{H}_{2} \mathrm{O}$ to produce $\mathrm{H}_{2}, \mathrm{CO}$, and $\mathrm{CO}_{2}$ at a stage prior to the inlet of stack- $\mathrm{A}$, and $\mathrm{H}_{2}$ is consumed in stacks- $\mathrm{A}$ and $-\mathrm{B}$ in series. The concentration of $\mathrm{H}_{2} \mathrm{O}$ in the downstream equilibrium compositions, shown in pie charts in Fig. 4a, are considerably smaller than with the oxide-ion conducting electrolyte (see supplementary material - Figure S1 online). However, the $\mathrm{H}_{2} \mathrm{O}$ concentration is sufficient for a reaction with $\mathrm{CO}$ (i.e., the water-gas shift reaction) if $\mathrm{H}_{2}$ is consumed, which results in supporting $\mathrm{H}_{2}$ resupply. Consequently, in the case of the proton-conducting electrolyte under the conditions assumed in this study, CO fills an adequate role as an indirect fuel, supporting the feasibility of critically-high efficiency.

\section{Discussion}

If the stacks have measurable gas leakage or ion-leakage, an upper limit of the Uf of not only the individual stacks but also the entire system should be considered. In such a case, optimizing the parameters with a constant $U f_{\mathrm{T}}$ as shown in Fig. 2a will be applicable to designing the multi-stage configuration. Figure 2 indicates that the electrical efficiency has a maximum at $r=0.5$ with the upper limit of $U f_{\mathrm{T}}$ of $90 \%$. Under this condition, $U f_{\mathrm{A}}$ and $U f_{\mathrm{B}}$ are calculated by the equations (3) and (4) to be $60 \%$ and $75 \%$, respectively.

On the other hands, if there are no needs for the upper limit of the $U f_{\mathrm{T}}$, only upper limits of the $U f_{\mathrm{A}}$ and $U f_{\mathrm{B}}$ should be considered. Without the upper limit of the $U f_{\mathrm{T}}$, the $U f_{\mathrm{A}}$ could be increased up to the 
a
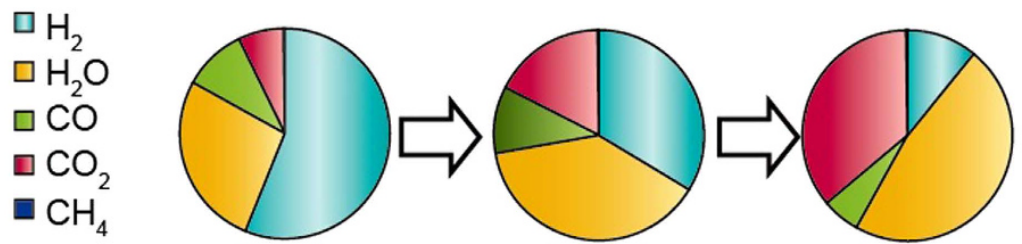

b
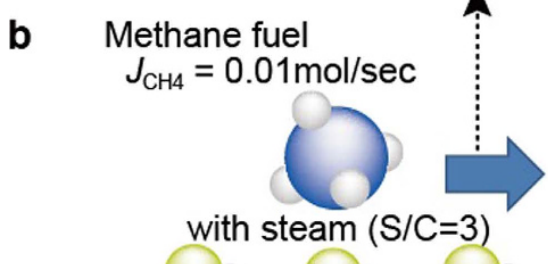

Stack- A
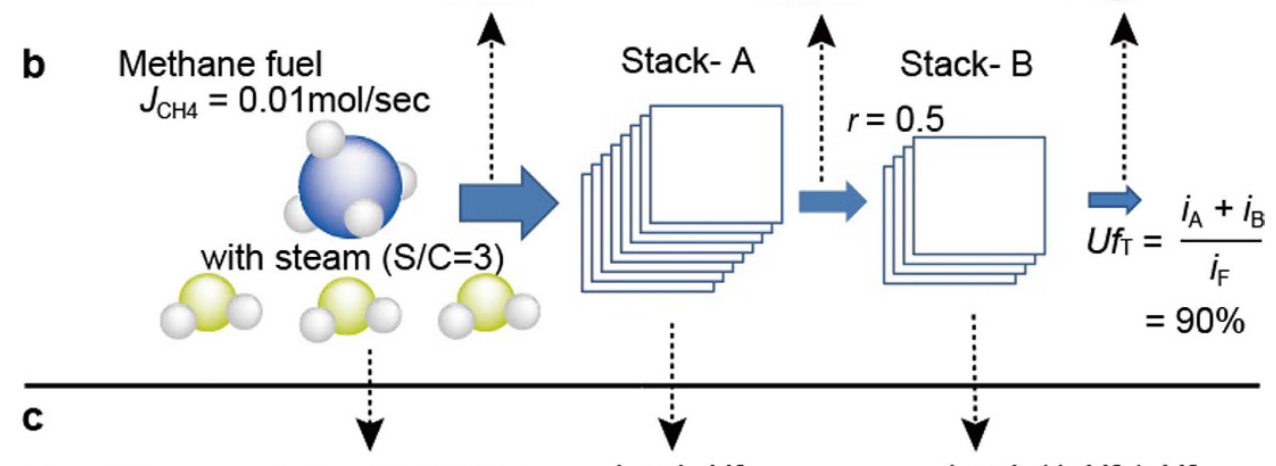

Faradaic current $i_{\mathrm{F}}=7.72 \cdot 10^{3} \mathrm{~A}$ (Equivalent Current)

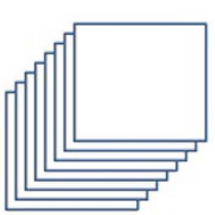

$$
=90 \%
$$

Cell voltage

$V_{\mathrm{A}}=0.944 \mathrm{~V}$

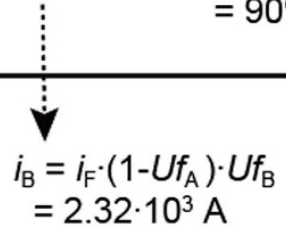

Power $\quad P_{\mathrm{CH} 4}=\Delta \mathrm{H} \cdot J_{\mathrm{CH} 4}=7.99 \mathrm{~kW} \quad P_{\mathrm{A}}=i_{\mathrm{A}} V_{\mathrm{A}}=4.4 \mathrm{~kW} \quad P_{\mathrm{B}}=i_{\mathrm{B}} \mathrm{V}_{\mathrm{B}}=2.1 \mathrm{~kW}$
Electric efficiency
\[ \frac{P_{\mathrm{A}}+P_{\mathrm{B}}}{P_{\mathrm{CH} 4}}=81.6 \% \text { (gross DC, LHV) } \]

Figure 4. Schematic representations of the conditions and results of the numerical experiment with the equilibrium fuel compositions calculated by the symbolic analysis. (a) Equilibrium compositions at the inlet and outlet of the stacks. (b) Schematics of the two-stage electrochemical oxidation of methane with the conditions of the numerical simulation. (c) Faradaic current, cell voltage, output electrical power, and electrical efficiency when methane is supplied at the rate of $0.01 \mathrm{~mol} \mathrm{sec}^{-1}$.

\begin{tabular}{|l|c|c|c|c|}
\hline \multicolumn{2}{|l|}{ Given parameters } & \multicolumn{3}{|c|}{ Results } \\
\hline $\boldsymbol{U} f_{\mathrm{A}}$ & $\boldsymbol{U} f_{\mathrm{B}}$ & $\boldsymbol{r}$ & $\boldsymbol{U} f_{\mathrm{T}}$ & $\eta_{\mathrm{e}}$ \\
\hline $60 \%$ & $75 \%$ & 0.500 & $90.0 \%$ & $81.4 \%$ \\
\hline $65 \%$ & $75 \%$ & 0.404 & $91.3 \%$ & $82.7 \%$ \\
\hline $70 \%$ & $75 \%$ & 0.321 & $92.5 \%$ & $83.7 \%$ \\
\hline $75 \%$ & $75 \%$ & 0.250 & $93.8 \%$ & $84.6 \%$ \\
\hline
\end{tabular}

Table 1. Electrical efficiency $\left(\eta_{\mathrm{e}}\right), \boldsymbol{U} f_{\mathrm{T}}$, and $\boldsymbol{r}$ as a function of $\boldsymbol{U} \boldsymbol{f}_{\mathrm{A}}$. The electrical efficiency increased from $81.6 \%$ to $84.6 \%$ (LHV, gross DC) when the $U f_{\mathrm{A}}$ increased from $60 \%$ to $75 \%$ with a fixed $U f_{\mathrm{B}}$ of $75 \%$

assumed upper limit of $75 \%$ with accompanying a rise in the electrical efficiency. The electrical efficiency increased from $81.6 \%$ to $84.6 \%$ (LHV, gross DC) with increasing the $U f_{\mathrm{A}}$ from $60 \%$ to $75 \%$ at a fixed $U f_{\mathrm{B}}$ of $75 \%$ (Table 1 ). The DC efficiency of $84.6 \%$ corresponds to a net AC efficiency of approximately $76.1 \%(\mathrm{LHV})$. Equations (1) and (2) indicate that the $U f_{\mathrm{T}}$ and $r$ also change with increasing $U f_{\mathrm{A}}$ with a fixed value of $U f_{\mathrm{B}}$ (Table 1).

We have investigated the combination of proton-conducting electrolyte and the multi-stage SOFCs by using the most basic configuration, i.e., two-stage configuration, and have successfully shown the valuable findings and promising results on the electrical efficiency. Based on the findings, additional technologies would be applicable for further improving the electrical efficiency, for example such as three- or higher numbers- stage configurations, and/or multi-stage supplies of fresh fuels to the downstream stacks mixed with the exhausted fuels from the upstream stacks. In those technologies, there are lots of variable parameters to be investigated further to achieve higher efficiencies. 
In this work, the proton-conducting electrolyte was assumed to have a protonic transport number of 1. In practice, however, the transport number depends on the material and temperature. Several approaches have been studied for increasing the protonic transport number and open-circuit voltage (OCV) to close to 1 and the theoretical value, respectively. For example, decreasing the operating temperature is effective ${ }^{24,25}$. Another approach is blocking oxide-ion by using Pd film which is reported to show OCV close to theoretical value and high performances ${ }^{26,27}$. Novel perovskite-type material with pure proton conductivity and chemical stability has also been reported ${ }^{28}$. These approaches are expected to produce an increased potential for realizing the evolved concept.

At high electrical efficiencies and high-temperatures, thermally self-sustaining operation is an important issue to consider ${ }^{29,30}$, and the smallest possible power-generating capacity of an SOFC system is determined mainly by a capability of a thermally self-sustaining operation. Here, a thermally self-sustaining operation entails maintaining the operation temperature of the system only by the heat generated from the system itself. In the case of the proton-conducting electrolyte, the electrochemical oxidation of hydrogen (exothermic reaction) will occur at the air electrode side. Therefore, under the thermally self-sustaining operation with sufficient margin, the stack with proton-conducting electrolyte will be cooled by air effectively, resulting in the BOP design similar to the case of the conventional stacks (based on oxide-ion conducting electrolytes). While the capability of a thermally self-sustaining operation and the smallest possible power-generating capacity of an SOFC system largely depend on the electrical efficiencies, operating temperatures, and structures of the stacks and systems, relatively much smaller power-generating capacities even with high electrical efficiencies are expected to be acceptable to SOFC systems (see supplementary material - Figure S2 online).

In summary, our study showed that simply switching the type of charge-carrier (ion) in the electrolyte from oxide-ion to proton yields remarkable advantages for the electrical efficiency under a high temperature multi-stage electrochemical oxidation mechanism. In this simple manner, an existing stack would be able to be used nearly as is except for changing a material in the layers with a thickness of approximately $10 \mu \mathrm{m}$ consisting of electrolyte sandwiched with active electrodes. This result indicates that proton-conducting solid electrolytes with high protonic transport numbers as well as with long-term stability will become key materials for the technical innovation in the energy field. The efficiency is considerably higher than that of the state-of-the-art several tens-of-MW-class MACC ${ }^{31}$, and would consist with a critically smaller electrical output capacity (see supplementary material - Figure S2 online).

\section{Methods}

Methods related to both the symbolic analysis and the numerical experiment. Twelve parameters are considered for the two-stage electrochemical oxidation: such as $U f_{\mathrm{T}}, U f_{\mathrm{A}}, U f_{\mathrm{B}}, r$, the temperature, the steam to carbon ratio $(S / C)$, the current densities of stacks- $\mathrm{A}$ and $-\mathrm{B}, A S R_{\mathrm{O}}$, the air utilization ratio (Uair) of stack- A, the Uair of stack- B, and partial pressure of $\mathrm{H}_{2} \mathrm{O}$ in air (see supplementary material - Figure S5-1 online). The following parameters are given assumed constants: the current density of stacks- A and -B is $0.25 \mathrm{Acm}^{-2}, \mathrm{~S} / \mathrm{C}$ is 3 , the temperature is $1,000 \mathrm{~K}$, the Uair of stacks- A and -B is $30 \%$, the partial pressure of $\mathrm{H}_{2} \mathrm{O}$ in air is $2 \%$, and the $A S R_{\mathrm{O}}$ is $0.383 \mathrm{ohm} \mathrm{cm}^{2}$.

The $A S R_{\mathrm{O}}$ is defined as the $A S R$ of the single-stack in individual use at sufficiently low Uf and Uair. The $A S R_{\mathrm{O}}$ value is assumed to be $0.383 \mathrm{ohm} \mathrm{cm}$. As generally observed, the $A S R$ estimated from the current-voltage characteristics has a $U f$ dependence. ASR used in this study, which is defined as $\Delta V$ (the difference between the cell voltage calculated by equation (5) and OCV) divided by the current density, also had a Uf dependence (Supplementary material Figure S5-2).

Considering the manufacturing cost of the stacks, stacks- A and -B were assumed to be stacked as an apparent single-stack with internal manifolds which enable the series connection of fuel supply as the two-stage configuration. Therefore, the current density was assumed to be equal for both stacks- A and $-\mathrm{B}$.

All the parameters are used as variable parameters, assumed constants, or dependent parameters in accordance with the aim of the analysis (supplementary material - Table S5 online). In Fig. 2, $U f_{\mathrm{T}}$ was assumed to be $90 \%, U f_{\mathrm{A}}$ and $U f_{\mathrm{B}}$ were dependent parameters, $r$ was used as a variable to optimize the dependent parameters under the upper limit of $U f_{\mathrm{T}}$. In Fig. 3 (two-stage configuration), and Fig. 4, $U f_{\mathrm{T}}$, $U f_{\mathrm{A}}, U f_{\mathrm{B}}$, and $r$ were assumed to be $90 \%, 60 \%, 75 \%, 0.5$, respectively, which gave the maximum efficiency under the upper limit of $U f_{\mathrm{T}}$ of $90 \%$. In Table $1, U f_{\mathrm{T}}$ and $r$ were dependent parameters, $U f_{\mathrm{B}}$ was fixed at $75 \%$ (assumed upper limit), $U f_{\mathrm{A}}$ was used as a variable to calculate the $U f_{\mathrm{A}}$ dependence of the electrical efficiency without the upper limit of $U f_{\mathrm{T}}$.

The cell voltage, $V_{\text {cell }}$, in each stack is approximately calculated by using the EMFs of the inlet and outlet of the cell corresponding to the fuel compositions, the area specific resistance $\left(A S R_{\mathrm{O}}\right)$, and the current density $(i)$ as described in equation (5).

$$
V_{\text {cell }}=\frac{E M F(\text { inlet })-E M F(\text { outlet })}{\log (E M F(\text { inlet }) / E M F(\text { outlet }))}-A S R_{O} \times i
$$

The first term on right side of this equation is the logarithmic mean of the EMFs at the inlet and outlet of the cell. The EMF is determined by the oxygen partial pressures, $\mathrm{PO}_{2}$, for the case of the oxide-ion conducting electrolyte, and the hydrogen partial pressures, $\mathrm{PH}_{2}$, for the case of the proton-conducting 
electrolyte, by equations (6) and (7), respectively, where $\mathrm{R}$ is the molar gas constant, and F is the Faraday constant. The effectiveness of the approximate expression, equation (5), has been confirmed by measurements of the dependence of the cell voltage on the $U f$ (see supplementary material - Figure S3 online).

$$
\begin{aligned}
& E M F(\mathrm{O})=\frac{\mathrm{RT}}{4 \mathrm{~F}} \ln \left(\frac{\mathrm{PO}_{2}(\text { air })}{\mathrm{PO}_{2}(\text { fuel })}\right) \\
& \operatorname{EMF}(\mathrm{H})=\frac{\mathrm{RT}}{2 \mathrm{~F}} \ln \left(\frac{\mathrm{PH}_{2}(\text { fuel })}{P \mathrm{H}_{2}(\text { air })}\right)
\end{aligned}
$$

For confirmation, the geometric and arithmetic means of EMFs were compared with the logarithmic mean for the approximate calculations of the cell voltage. The two types of means yielded nearly the same voltage as that given by the logarithmic mean used for equation (5) (see supplementary material - Figure S4 online); thus, these averaging methods are also appropriate in addition to the logarithmic mean for the approximate calculation of the cell voltage.

Parametric study based on a symbolic analysis. MAPLE 17 was used for the parametric study based on the symbolic analysis. The equilibrium composition of fuel including $\mathrm{PO}_{2}$ and $\mathrm{PH}_{2}$ at each stage used in equations (6) and (7) is determined by three equilibrium reactions (8)-(10) and the elemental mole fractions of $\mathrm{C}, \mathrm{H}$, and $\mathrm{O}$.

$$
\begin{gathered}
\mathrm{H}_{2}+1 / 2 \mathrm{O}_{2}=\mathrm{H}_{2} \mathrm{O} \\
\mathrm{CO}+1 / 2 \mathrm{O}_{2}=\mathrm{CO}_{2} \\
\mathrm{CH}_{4}+\mathrm{H}_{2} \mathrm{O}=3 \mathrm{H}_{2}+\mathrm{CO}
\end{gathered}
$$

The Gibbs free energies of the reactions were taken from the JANAF table for the symbolic analysis using MAPLE 17. The element mole fractions at the inlet and outlet of the respective stacks were determined as a function of the independent variables, $U f_{\mathrm{T}}$ and $r$.

Calculation of the electrical efficiency in the case of the symbolic analysis. Electrical efficiency (gross DC), $\eta_{\mathrm{dc}}$ (symbolic), was calculated by using equation (11) as a function of $V_{\mathrm{ave}}, U f_{\mathrm{T}}$, and $\mathrm{dH}$, where $\mathrm{dH}$ is the standard enthalpy change of the oxidation reaction of $\mathrm{CH}_{4}$ at $298.15 \mathrm{~K}$ and $V_{\text {ave }}$ is a weighted average of the cell voltages of stack- $\mathrm{A}\left(V_{\mathrm{A}}\right)$ and stack- $\mathrm{B}\left(V_{\mathrm{B}}\right)$ as expressed by equation (12) (see supplementary material - Figure S6 online). The conversion loss from DC power to AC power was assumed to be $10 \%$, so the net AC electrical efficiency, $\eta_{\mathrm{ac}}$, was calculated by equation (13). In the case of $700 \mathrm{~W}$-class combined heat and power systems with fuel cells for residential use, the power loss from DC to AC was reported to be $100 \mathrm{~W}$ (from 800 to $700 \mathrm{~W}$ ), which corresponds to a loss of $12.5 \%{ }^{32}$. In the case of $1.5 \mathrm{~kW}$-class systems, the efficiency loss from DC to AC was reported to be 8 percentage point (from $68 \%$ to $60 \%$ ), which corresponds to a loss of $11.8 \%{ }^{10,11}$. The evolved concept we discussed in this study was based on the premise of a larger generating capacity of several- $\mathrm{kW}$ or more. Because the power loss ratio tends to decrease with an increase in the generating capacity, we assumed the power loss ratio of $10 \%$ in equation (13).

$$
\begin{gathered}
\eta_{\mathrm{dc}}(\text { symbolic })=\left(8 \mathrm{~F} \times V_{\mathrm{ave}} \times U f_{\mathrm{T}}\right) / \mathrm{dH} \\
V_{\mathrm{ave}}=\left(V_{\mathrm{A}}+r \times V_{\mathrm{B}}\right) /(1+r) \\
\eta_{\mathrm{ac}}=\eta_{\mathrm{dc}}(\text { symbolic }) \times 0.9
\end{gathered}
$$

Numerical experiment (process simulation). A process simulation based on the numerical analysis of the total system process, which includes not only two-stage SOFC stacks but also auxiliary devices such as heat exchangers, a fuel reformer, a fuel combustor, and a vaporizer, and a heat recovery unit, the so-called balance of plant (BOP), was numerically modeled at the steady state by using AspenPlus Ver. 7.3 (see supplementary material - Figure S7 online). Equilibrium composition of the fuel at each stage was calculated by using a thermodynamics database from AIChE, which contains the thermodynamic functions and equilibrium parameters of the vapour-phase molecules appearing in this study. After reforming, fuel was immediately supplied to stack- A followed by stack- B, and the fuel was finally subject to complete combustion at the fuel combustor. The flow lines of air supply to the stacks were in parallel. 
Methane, air, and water were supplied to the inlet of the system at $298.15 \mathrm{~K}$. The flow rate of methane was set to $1.0 \times 10^{-2} \mathrm{~mol} \mathrm{sec}-1$ mixed with water at a flow rate of $3.0 \times 10^{-2} \mathrm{~mol} \mathrm{sec}^{-1}$. The system operating conditions were defined as follows: $S / C$ was 3 , the air utilization ratio of each stack was $30 \%$, and the excess air ratio in the fuel combustor was 1.05. Several auxiliary devices were thermally integrated in the system. The thermal energies needed for the reforming reaction, the vaporization of water, and the pre-heating of air and fuel, were covered by the heat generated at the stacks and the combustion chamber under thermal management using several heat exchangers (see supplementary material - Figure S7 online).

Calculation of electrical efficiency in the case of the numerical analysis. The faradic currents in stacks- A and -B are given by equations (14) and (15) when methane fuel is supplied to stack- A at $M_{\mathrm{CH} 4} \mathrm{~mol} \mathrm{sec}^{-1}$.

$$
\begin{gathered}
i_{\mathrm{A}}[\mathrm{A}]=M_{\mathrm{CH} 4}\left[\mathrm{~mol} \mathrm{sec}^{-1}\right] \times U f_{\mathrm{A}}[-] \times 8 \mathrm{~F}\left[\mathrm{Cmol}^{-1}\right] \\
i_{\mathrm{B}}[\mathrm{A}]=M_{\mathrm{CH} 4}\left[\mathrm{~mol} \mathrm{sec}^{-1}\right] \times\left(1-U f_{A}[-]\right) \times U f_{\mathrm{A}}[-] \times 8 F\left[\mathrm{Cmol}^{-1}\right]
\end{gathered}
$$

The electrical output powers $P_{\mathrm{A}}$ and $P_{\mathrm{B}}$ in stacks- A and -B were calculated by equations (16) and (17). Using the electrical output powers and enthalpy of the supplied methane with a flow rate of $M_{\mathrm{CH} 4}$, the electrical efficiency (gross DC), $\eta_{\mathrm{dc}}$ (numeric), was calculated by equation (18)

$$
\begin{gathered}
P_{\mathrm{A}}=i_{\mathrm{A}} \times V_{\mathrm{A}} \\
P_{\mathrm{B}}=i_{\mathrm{B}} \times V_{\mathrm{B}} \\
\eta_{\mathrm{dc}}(\text { numeric })=\left(P_{A}+P_{B}\right) /\left(\mathrm{dH} \times M_{\mathrm{CH} 4}\right)
\end{gathered}
$$

\section{References}

1. Steele, B. C. H. Fuel-cell technology-Running on natural gas. Nature 400, 619-+(1999).

2. Steele, B. C. H. \& Heinzel, A. Materials for fuel-cell technologies. Nature 414, 345-352 (2001).

3. Payne, R., Love, J. \& Kah, M. CFCL's BlueGen Product. Solid Oxide Fuel Cells 12 (Sofc Xii) 35, 81-85 (2011).

4. Choudhury, A., Chandra, H. \& Arora, A. Application of solid oxide fuel cell technology for power generation-A review. Renew. Sust. Energ. Rev. 20, 430-442 (2013).

5. Suzuki, M., Takuwa, Y., Inoue, S. \& Higaki, K. Durability Verification of Residential SOFC CHP System. Solid Oxide Fuel Cells 13 (Sofc-Xiii) 57, 309-314 (2013).

6. Elangovan, S., Hartvigsen, J. \& Khandkar, A. Efficiency enhancement in fuel cells: Multistage oxidation concept. J. Electrochem. Soc. 144, 3337-3342 (1997).

7. Frost, L. J., Privette, R. M. \& Khandkar, A. C. Progress in the planar CPn SOFC system design. J. Power Sources 61, 135-139 (1996).

8. Hirschenhofer, J. H., D. B. S., Engleman, R. R. \& Klett, M. G. Fuel Cell Hndbook Forth Edition, 7.29-7.33 (1998) Available at: http://physics.oregonstate.edu/ hetheriw/energy/topics/doc/electrochemistry/fc/basic/fuel_cell_handbook_fourth_ed_fed_ energy_tech_center_99.pdf (Accessed: 27th March 2015).

9. Ando, Y., Miyamoto, H., Minemoto, M. Numerical Analysis for High Efficiency Internally Reverse SOFC. Kagakukougaku 37, 447-453 (2011).

10. Jonathan Love, S. A., David Selvey, Xiao Zheng, Lars Christiansen. Development of SOFC Stacks at Ceramic Fuel Cells Limited. Solid Oxide Fuel Cells 11 (Sofc-Xi) 25, 115-124 (2009).

11. Payne, R., Love, J. \& Kah, M. Generating Electricity at 60\% Electrical Efficiency from 1-2 kWe SOFC Products. Solid Oxide Fuel Cells 11 (Sofc-Xi) 25, 231-239 (2009).

12. Benamira, M., Thommy, L., Moser, F., Joubert, O. \& Caldes, M. T. New anode materials for IT-SOFC derived from the electrolyte BaIn0.3Ti0.7O2.85 by lanthanum and manganese doping. Solid State Ion. 265, 38-45 (2014).

13. Patakangas, J., Ma, Y., Jing, Y. F. \& Lund, P. Review and analysis of characterization methods and ionic conductivities for lowtemperature solid oxide fuel cells (LT-SOFC). J. Power Sources 263, 315-331 (2014).

14. Vladikova, D. et al. Application of yttrium doped barium cerate for improvement of the dual membrane SOFC design. Int. J. Hydrog. Energy 39, 21561-21568, (2014).

15. Yang, L. et al. Enhanced Sulfur and Coking Tolerance of a Mixed Ion Conductor for SOFCs: BaZr0.1Ce0.7Y0.2-xYbxO3-delta. Science 326, 126-129 (2009).

16. Wachsman, E. D. \& Lee, K. T. Lowering the Temperature of Solid Oxide Fuel Cells. Science 334, 935-939 (2011).

17. Lin, Y. et al. Evaluation of $\mathrm{Ba} 0.5 \mathrm{Sr} 0.5 \mathrm{Co} 0.8 \mathrm{Fe} 0.2 \mathrm{O} 3$-delta as a potential cathode for an anode-supported proton-conducting solid-oxide fuel cell. J. Power Sources 180, 15-22 (2008).

18. Li, M. L., Ni, M., Su, F. \& Xia, C. R. Proton conducting intermediate-temperature solid oxide fuel cells using new perovskite type cathodes. J. Power Sources 260, 197-204 (2014).

19. Bonanos, N., Knight, K. S. \& Ellis, B. Perovskite solid electrolytes - structure, transport-properties and fuel-cell applications. Solid State Ion. 79, 161-170 (1995).

20. Bi, L., Fabbri, E. \& Traversa, E. Effect of anode functional layer on the performance of proton-conducting solid oxide fuel cells (SOFCs). Electrochem. Commun. 16, 37-40 (2012).

21. Yoo, Y. \& Lim, N. Performance and stability of proton conducting solid oxide fuel cells based on yttrium-doped barium ceratezirconate thin-film electrolyte. J. Power Sources 229, 48-57 (2013).

22. Lei Yang, C. Z., Wang, Shizhong, Cheng, Zhe \& Meilin Liu, A. Novel Composite Cathode for Low-Temperature SOFCs Based on Oxide Proton Conductors. Advanced Material 20, 3280-3283 (2008). 
23. Ivers-Tiffee, E. et al. Performance Analysis and Development Strategies for Solid Oxide Fuel Cells. Solid Oxide Fuel Cells 12 (Sofc Xii) 35, 1965-1973 (2011).

24. Ding, H. P., Xie, Y. Y. \& Xue, X. J. Electrochemical performance of BaZr0.1Ce0.7Y0.1Yb0.1O3-delta electrolyte based protonconducting SOFC solid oxide fuel cell with layered perovskite PrBaCo2O5+delta cathode. J. Power Sources 196, 2602-2607 (2011).

25. Qian, J., Sun, W. P., Shi, Z., Tao, Z. T. \& Liu, W. Chemically stable BaZr0.7Pr0.1Y0.2O3-delta-BaCe0.8Y0.2O3-delta bilayer electrolyte for intermediate temperature solid oxide fuel cells. Electrochim. Acta 151, 497-501 (2015).

26. Ito, N., Iijima, M., Kimura, K. \& Iguchi, S. New intermediate temperature fuel cell with ultra-thin proton conductor electrolyte. J. Power Sources 152, 200-203 (2005).

27. Ito, N. et al. Electrochemical analysis of hydrogen membrane fuel cells. J. Power Sources 185, 922-926 (2008).

28. Kannan, R., Singh, K., Gill, S., Furstenhaupt, T. \& Thangadurai, V. Chemically Stable Proton Conducting Doped BaCeO3 -No More Fear to SOFC Wastes. Sci Rep 3, 5 (2013).

29. Shao, Z. P. et al. A thermally self-sustained micro solid-oxide fuel-cell stack with high power density. Nature 435, 795-798 (2005).

30. Watanabe, N., Ooe, T. \& Ishihara, T. Design of thermal self supported $700 \mathrm{~W}$ class, solid oxide fuel cell module using, LSGM thin film micro tubular cells. J. Power Sources 199, 117-123 (2012).

31. Rao, A. D. \& Francuz, D. J. An evaluation of advanced combined cycles. Appl. Energy 102, 1178-1186 (2013).

32. Otomo, J., Oishi, J., Mitsumori, T., Iwasaki, H. \& Yamada, K. Evaluation of cost reduction potential for $1 \mathrm{~kW}$ class SOFC stack production: Implications for SOFC technology scenario. Int. J. Hydrog. Energy 38, 14337-14347 (2013).

\section{Acknowledgements}

This research is supported by The Japan Science and Technology Agency (JST) through its "Center of Innovation Science and Technology-based Radical Innovation and Entrepreneurship Program (COI Program)."

\section{Author Contributions}

Y.M. designed the study and concept and performed the symbolic analysis. Y.T. performed the numeric analysis (process simulation). T.S. and T.H. assisted with the analyses. H.M. discussed the results in initial and subsequent stages to advance the study. S.T. and K.S. assisted with the design of the concept. Y.M. and Y.T. wrote the manuscript. All authors discussed the results and commented on the manuscript.

\section{Additional Information}

Supplementary information accompanies this paper at http://www.nature.com/srep

Competing financial interests: The authors declare no competing financial interests.

How to cite this article: Matsuzaki, Y. et al. Effect of proton-conduction in electrolyte on electric efficiency of multi-stage solid oxide fuel cells. Sci. Rep. 5, 12640; doi: 10.1038/srep12640 (2015).

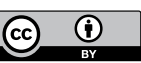

This work is licensed under a Creative Commons Attribution 4.0 International License. The images or other third party material in this article are included in the article's Creative Commons license, unless indicated otherwise in the credit line; if the material is not included under the Creative Commons license, users will need to obtain permission from the license holder to reproduce the material. To view a copy of this license, visit http://creativecommons.org/licenses/by/4.0/ 